\title{
Tätheten av gransångare Phylloscopus c. collybita och lövsångare Phylloscopus trochilus i ett sydsvenskt villaområde
}

\author{
Density of Chiffchaffs Phylloscopus c. collybita and Willow Warblers Phylloscopus \\ trochilus in a south Swedish villa suburb
}

SVEN MARLING

\begin{abstract}
The expansion of the Chiffchaff Phylloscopus c. collybita in southern Sweden during the last decades is well documented. Regionally the densities of the Chiffchaff now even exceed the densities of the ubiquitous Willow Warbler Phylloscopus trochilus. However, there are few quantitative studies on Chiffchaff densities, not least from urban areas. During spring 2013 a survey of singing Chiffchaffs and Willow Warblers, complemented by territory mapping, was conducted in three villa suburb areas (total ea $1.27 \mathrm{~km}^{2}$ ) and a nearby recreational area in the southwestern parts of the city of Malmö, Sweden. The villa areas held a substantially higher number of Chiff-

chaffs (16.5 pairs $/ \mathrm{km}^{2}$ ) than Willow Warblers (6.3 pairs/ $\mathrm{km}^{2}$ ). In one villa sub-area, with little undergrowth and denser housing, there were no Willow Warblers at all, in contrast to the recreational area close to the villa areas, where the Willow Warbler dominated $\left(10.9\right.$ pairs $\left./ \mathrm{km}^{2}\right)$. The Chiffchaff had its highest density $\left(18.7\right.$ pairs $\left./ \mathrm{km}^{2}\right)$ in the sub-area that had the largest trees. Thus, in the investigated villa suburb, the Chiffchaff clearly outnumbered the Willow Warbler as a breeding bird.

Sven Marling, Onsdagsgatan 1,216 19 Malmö, Sweden. Sven.Marling@lmgilund.se
\end{abstract}

Received 9 March 2014, Accepted 13 October Editor: Å. Lindström

\section{Inledning}

Den sydliga gransångarens Phylloscopus c. collybita expansion i Sverige de senaste decennierna är både välkänd och väldokumenterad (Lindström et al. 2007, Ottosson et al. 2012). Gransångarens "styltiga" sång är nu ett vanligt inslag i ljudbilden en vårmorgon i sydvästligaste Sverige och på sina håll verkar gransångaren nu till och med vara vanligare än Sveriges vanligaste fågel, lövsångaren Phylloscopus trochilus. För att undersöka detta mer i detalj inventerade jag under våren 2013 gransångare och lövsångare i några villaområden i sydvästra Malmö.

\section{Metodik}

Inventeringen genomfördes i stadsdelarna Bellevue $\left(0,53 \mathrm{~km}^{2}\right)$, Nya Bellevue $\left(0,43 \mathrm{~km}^{2}\right)$ och Västervång $\left(0,31 \mathrm{~km}^{2}\right)$ i sydvästra Malmö $\left(\sim 55^{\circ} 35^{\prime} \mathrm{N}\right.$, $12^{\circ} 57^{\circ} \mathrm{E}$, Figur 1). Alla tre områdena är villaområden som bebyggts från början av 1900-talet och framåt. Flygfoton över området indikerar att i Bellevueområdet ligger villorna något glesare och mer oregelbundet placerade och trädgårdarna ser lummigare ut än i Nya Bellevue. I området Väs- tervång, som ger det mest öppna intrycket, är villorna i ett kvarter ofta placerade med husen i täta rader längs gatorna och kvarteren har trädgårdar som vetter mot varandra. Som jämförelseområde

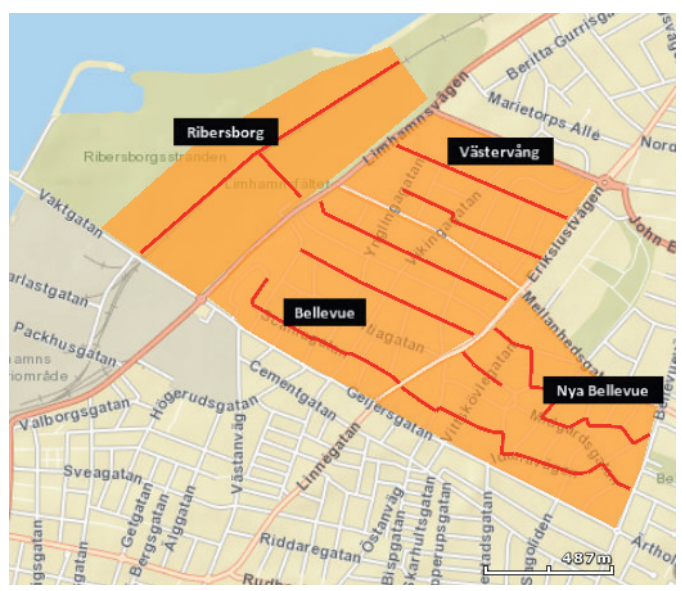

Figur 1. Inventeringsområden och inventeringslinjer i Malmö våren 2013.

The survey areas and line transects in Malmö, Sweden, in spring 2013. 


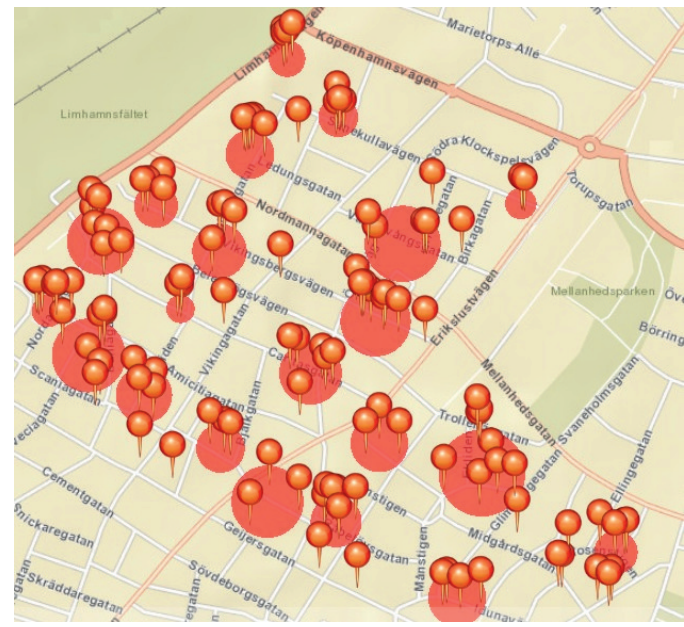

Figur 2. Gransångarobservationer ("nålar") och revir (röda cirklar) i studieområdet.

Observations ("pins") and territories (red circles) of Chiffchaffs in the study area.

valdes ett anslutande område på Ribersborgsfältet $\left(0,46 \mathrm{~km}^{2}\right)$. Förutom stora gräsytor inkluderar detta område en trädridå längs banvallen på den gamla nerlagda järnvägen Limhamn-Malmö, samt ett par större träddungar.

Inventeringarna genomfördes på cykel vid 8 tillfällen mellan den 28 april och den 17 maj. Vid samtliga tillfällen påbörjades inventeringen runt kl. 05.00 och den tog ungefär 2 timmar att genomföra. Avståndet mellan inventeringslinjerna (Figur 1) planerades så att hela området täcktes in. Observatören beräknades kunna höra sjungande făglar till något över $100 \mathrm{~m}$ avstånd från "linjen". Endast sjungande individer av gran- och lövsångare noterades. Då vårflyttningen inte var över vid inventeringens start, speciellt inte för lövsångaren, så

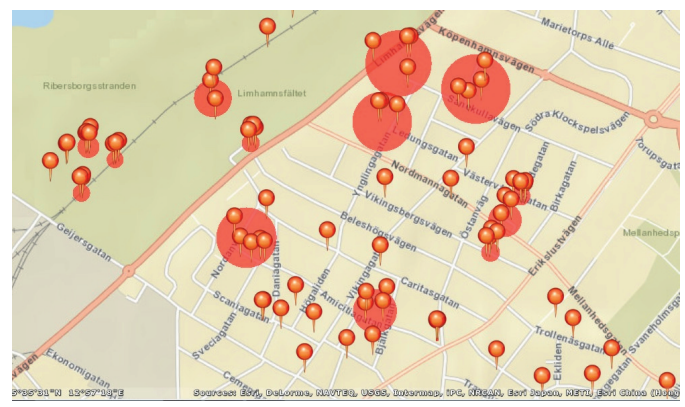

Figur 3. Lövsångarobservationer ("nålar") och revir (röda cirklar) i studieområdet.

Observations ("pins") and territories (red circles) of Willow Warblers in the study area. utökades undersökningen till att inte bara jämföra antalet sjungande individer av gran- och lövsångare vid varje inventering, utan att också försöka beräkna antalet revir av respektive art i undersökningsområdet. Alla till synes permanenta revir (minst 3 noteringar av sjungande fågel) prickades ut på karta (Figur 2 och 3).

För att underlätta vid revirbestämningen så noterades $\mathrm{i}$ alla delområdena från inventering $\mathrm{nr} 2$ och framåt i vilken typ av träd den sjungande fågeln satt. Speciellt i början av perioden var trädslaget inte lätt att bestämma på avstånd, så kategorierna "barrträd", "björk"," bok" och "annat lövträd" användes. Ibland satt den sjungande fågeln i en grupp av träd där fågeln inte kunde upptäckas eller sångplatsen var skymd av något hinder, dessa fåglar har noterats under "sångplats ej fastställd".

Väderbetingelserna då inventeringarna genomfördes dominerades av klart väder och vindstilla förhållanden. Ett par inventeringar genomfördes vid lätt vind, temperaturen låg generellt mellan 2 och 11 plusgrader. Medelvärden i resultatdelen presenteras med \pm 1 standardavvikelse.

\section{Resultat}

Antalet sjungande gran- och lövsångare har summerats för villakvarteren var för sig och jämförelseområdet på Ribersborgsfältet för sig. Antalet gransångare $\mathrm{i}$ de tre villaområdena varierade mellan 11 och 18 individer per inventeringstillfälle, med ett medelvärde på 15,2 $\pm 2,8$ (Tabell 1). Antalet sjungande lövsångare varierade mellan 4 och 20 individer (medel 7,1 $\pm 5,5$ ). Endast enstaka sjungande gransångare noterades på Ribersborgs-områ$\operatorname{det}$ (medel 0,5 $\pm 0,5$, Tabell 2). Antalet sjungande

Tabell 1. Antal sjungande gran- och lövsångare i Nya Bellevue, Bellevue och Västervång.

Number of singing Chiffchaff and Willow Warbler in the areas of Nya Bellevue, Bellevue and Västervaing, in April (apr) and May (maj).

\begin{tabular}{cccc}
\hline $\begin{array}{c}\text { Inventering } \\
\text { Survey }\end{array}$ & $\begin{array}{c}\text { Datum } \\
\text { Date }\end{array}$ & $\begin{array}{c}\text { Gransångare } \\
\text { Chiffchaff }\end{array}$ & $\begin{array}{c}\text { Lövsångare } \\
\text { Willow Warbler }\end{array}$ \\
\hline 1 & 28 apr & 12 & 5 \\
2 & $1 \mathrm{maj}$ & 14 & 4 \\
3 & $4 \mathrm{maj}$ & 18 & 9 \\
4 & $9 \mathrm{maj}$ & 11 & 20 \\
5 & $12 \mathrm{maj}$ & 18 & 6 \\
6 & $14 \mathrm{maj}$ & 16 & 5 \\
7 & $15 \mathrm{maj}$ & 18 & 4 \\
8 & $17 \mathrm{maj}$ & 15 & 4 \\
\hline Summa/Total & & 122 & 57 \\
\hline
\end{tabular}


Tabell 2. Antal sjungande gran- och lövsångare i Ribersborgsområdet.

Number of singing Chiffchaff and Willow Warbler in Ribersborg area, in April (apr) and May (maj).

\begin{tabular}{cccc}
\hline $\begin{array}{c}\text { Inventering } \\
\text { Survey }\end{array}$ & $\begin{array}{c}\text { Datum } \\
\text { Date }\end{array}$ & $\begin{array}{c}\text { Gransångare } \\
\text { Chiffchaff }\end{array}$ & $\begin{array}{c}\text { Lövsångare } \\
\text { Willow Warble }\end{array}$ \\
\hline 1 & $28 \mathrm{apr}$ & 1 & 1 \\
2 & $1 \mathrm{maj}$ & 1 & 3 \\
3 & $4 \mathrm{maj}$ & 0 & 2 \\
4 & $9 \mathrm{maj}$ & 0 & 10 \\
5 & $12 \mathrm{maj}$ & 1 & 2 \\
6 & $14 \mathrm{maj}$ & 1 & 3 \\
7 & $15 \mathrm{maj}$ & 0 & 3 \\
8 & $17 \mathrm{maj}$ & 0 & 2 \\
\hline Summa/Total & & 4 & 26 \\
\hline
\end{tabular}

lövsångare varierade mellan 1 och 10 individer (medel 3,3 $\pm 2,8$ ).

Inventering nr 4 skiljde sig från de övriga inventeringarna genom att ha ett stort antal sjungande lövsångare (Tabell 1 och 2). Troligen rörde det sig om en rejäl påspädning av rastande fåglar på flyttning denna dag och observationerna från denna dag användes därför inte till att bestämma antalet revir.

Det totala antalet gransångarrevir i villaområdena var 21 (Tabell 3). För lövsångaren noterades totalt 8 revir i samma område, varav ett delområde, Nya Bellevue, helt saknade revir. I jämförelseområdet Ribersborg noterades inget gransångarrevir, men fem revir lövsångare (Tabell 3). För de tre villaområdena tillammans var revirtätheten 16,5 par/ $\mathrm{km}^{2}$ för gransångaren och $6,3 \mathrm{par} / \mathrm{km}^{2}$ för lövsångaren.

Under inventeringarna så noterades också, om möjligt, var den sjungande fågeln satt (Tabell 4 och 5). För båda arterna gällde att antalet ej säkerställda sångplatser var stort, $23 \%$ för gransångare och $44 \%$ för lövsångare, så resultatet skall tolkas med viss försiktighet. Av de fastställda sångplatserna framgår dock att gransångaren använder sig av ett brett spektrum av olika lövträd som sångplats, men de påträffas även i barrträd. Lövsångaren noterades däremot inte vid något tillfälle som säkert sittande i ett barrträd.

\section{Diskussion}

Antalet revir av gransångare i det undersökta området var klart fler än antalet revir av lövsångare, nämligen 16,5 mot $6,3 \mathrm{par} / \mathrm{km}^{2}$. Något tidigare motsvarande inventeringsresultat från Malmö är inte känt. Man kan dock notera att vid en inventering år 1991 i Malmös tätortsdominerade grannkommun Burlöv, fann man inte ett enda häckande par gransångare, medan lövsångartätheten var 2,2 par $/ \mathrm{km}^{2}$ (Bengtsson \& Larsson 1991). Skillnaden i antalet gransångare mellan de två studierna är väl i linje med vad vi vet om artens sentida historik i Sydsverige.

I statistiken från Svensk Fågeltaxering kan den sydliga gransångarens expansion i Sverige följas från 1975 och rasen ökade i genomsnitt med 9,6\% per år under perioden (Green \& Lindström 2014). Vid inventeringarna i Skåne för Svensk Fågelatlas 1974-1984 konstaterades det säkra häckningar av gransångare i bara 3\% av inventeringsrutorna (Svensson m.fl. 1999) och populationen var "säkert under 100 par" (Bengtsson \& Green 2013). Den huvudsakliga utbredningen låg då $\mathrm{i}$ den nordvästra delen av landskapet. Vid de uppföljande inventeringarna för Skånes Fågelatlas under 2000-talet hade arten spritt sig över landskapet och noterades i $91 \%$ av de skånska rutorna och populationen uppkattades till 14000 par (Ottosson m.fl. 2012, Bengtsson \& Green 2013).

Som ytterligare jämförelse till den nu genomförda studien i Malmö kan nämnas en inventering på

Tabell 3. Antal revir respektive revirtäthet (revir/km2) av gransångare och lövsångare i de olika undersökningsområdena.

Number of territories and territory density (territories $/ \mathrm{km} 2$ ) of Chiffchaff and Willow Warbler in the study areas.

\begin{tabular}{lrrrr}
\hline \multirow{2}{*}{$\begin{array}{l}\text { Område } \\
\text { Area }\end{array}$} & $\begin{array}{l}\text { Gransångare Chiffchaff } \\
\text { Revir }\end{array}$ & $\begin{array}{c}\text { Lövsångare Willow Warbler } \\
\text { Revir }\end{array}$ & $\begin{array}{r}\text { Täthet } \\
\text { Density }\end{array}$ \\
\hline Bellevue & 10 & 18,7 & 3 & 5,6 \\
Nya Bellevue & 6 & 13,5 & 0 & 0 \\
Västervång & 5 & 16,2 & 5 & 16,2 \\
\hline Totalt villaområdena & & & & 6,3 \\
Total for villa areas & 21 & 16,5 & 8 & 10,9 \\
\hline Ribersborg & 0 & 0 & 5 & \\
\hline
\end{tabular}


Tabell 4. Sångplatser för gransångare, summerat för alla delområden. Sångplats noterades ej under inventering 1. Song posts for Chiffchaffs, all areas combined (not recorded during survey 1).

\begin{tabular}{ccccccc}
\hline $\begin{array}{c}\text { Inventering } \\
\text { Survey }\end{array}$ & $\begin{array}{c}\text { Datum } \\
\text { Date }\end{array}$ & $\begin{array}{c}\text { Björk } \\
\text { Birch }\end{array}$ & $\begin{array}{c}\text { Bok } \\
\text { Beech }\end{array}$ & $\begin{array}{c}\text { Annat lövträd } \\
\text { Deciduous } \\
\text { tree }\end{array}$ & $\begin{array}{c}\text { Barrträd } \\
\text { Coniferous } \\
\text { tree }\end{array}$ & $\begin{array}{c}\text { Ej fastställd } \\
\text { Not } \\
\text { detectable }\end{array}$ \\
\hline 2 & $1 \mathrm{maj}$ & 1 & 1 & 1 & 1 & 11 \\
3 & $4 \mathrm{maj}$ & 5 & 4 & 3 & 5 & 1 \\
4 & $9 \mathrm{maj}$ & 2 & 2 & 4 & 0 & 3 \\
5 & $12 \mathrm{maj}$ & 1 & 3 & 13 & 0 & 2 \\
6 & $14 \mathrm{maj}$ & 2 & 4 & 8 & 1 & 2 \\
7 & $15 \mathrm{maj}$ & 1 & 4 & 7 & 1 & 5 \\
8 & 17 maj & 0 & 4 & 9 & 0 & 2 \\
\hline Summa Total & & 12 & 22 & 45 & 8 & 26 \\
\hline
\end{tabular}

Kullaberg 2004 då man fann 10,7 par gransångare/ $\mathrm{km}^{2}$ och 10,8 par lövsångare $/ \mathrm{km}^{2}$ (Peterz \& Rellmar 2007). Resultaten indikerar att gransångaren har en relativt sett större förkärlek för villakvarter än lövsångaren och att gransångartätheten i villakvarter kan vara högre än i skogsmiljö. Dessutom är de $16,5 \mathrm{par} / \mathrm{km}^{2}$ som uppmättes troligen det högsta värdet funnet i Sverige på en så pass stor inventeringsyta, för någon av de två raserna (Peterz \& Rellmar 2007, Ottosson m.fl. 2012).

I Centraleuropa där gransångaren är etablerad sedan länge visar inventeringsresultat att gransångaren är mycket vanlig i urbana miljöer, men tätheten varierar mycket mellan städer. Baserat på atlasarbete 2005-2009 uppskattas den generella tätheten i Hamburg till mellan 7 och $21 \mathrm{par} / \mathrm{km}^{2}$, medan motsvarande siffror för Berlin bara var 0,4-1,0 par $/ \mathrm{km}^{2}$ (Gedeon et al. 2014). I undersökningar gjorda under perioden 1960-1990 i mellersta och norra Tyskland återfanns gransångaren i $96 \%$ av parkerna med en medeltäthet på 31 par/ $\mathrm{km}^{2}$. I förortsområden och villaområden med trädgårdar fanns den representerad i $74 \% \mathrm{av}$ de under- sökta områdena med ett medelvärde på $11 \mathrm{par} / \mathrm{km}^{2}$ (Flade 1994). Den nu uppmätta tätheten i Malmö, $16,5 \mathrm{par} / \mathrm{km}^{2}$ står sig alltså redan väl i jämförelse och man kan undra om tätheten i Malmö redan nått sin topp?

För lövsångaren anger Ottosson m.fl. (2012) att tätheten $\mathrm{i}$ bebyggelse $\mathrm{i}$ hela landet ligger på 10-20 $\mathrm{par} / \mathrm{km}^{2}$. I de undersökta villaområdena i Malmö var medelvärdet $6,3 \mathrm{par} / \mathrm{km}^{2}$. I optimala miljöer kan dock tätheten för lövsångare vara så hög som 100-250 par $/ \mathrm{km}^{2}$ (till exempel äldre hyggen med tät björksly, Ottosson m.fl. 2012).

Vid inventeringarna i villaområdena var antalet sjungande gransångare högre än antalet sjungande lövsångare vid sju tillfällen av åtta (Tabell 1). Det enda avvikande resultatet var inventering $\mathrm{nr} 4$ den 9 maj då 20 sjungande lövsångare noterades mot normala 5-6. En rimlig förklaring till det stora antalet observationer är att det rörde sig om flyttande fåglar som rastade tillfälligt. Vid nästa inventering tre dagar senare var lövsångarantalet tillbaka i nivå med tidigare inventeringar. Om inventering $\mathrm{nr} 4$ exkluderas så gjordes 111 observationer av sjung-

Tabell 5. Sångplatser för lövsångare, summerat för alla delområden. Sångplats noterades ej under inventering 1. Song posts for Willow Warblers, all areas combined (not recorded during survey 1).

\begin{tabular}{ccccccc}
\hline $\begin{array}{c}\text { Inventering } \\
\text { Survey }\end{array}$ & $\begin{array}{c}\text { Datum } \\
\text { Date }\end{array}$ & $\begin{array}{c}\text { Björk } \\
\text { Birch }\end{array}$ & $\begin{array}{c}\text { Bok } \\
\text { Beech }\end{array}$ & $\begin{array}{c}\text { Annat lövträd } \\
\text { Deciduous } \\
\text { tree }\end{array}$ & $\begin{array}{c}\text { Barrträd } \\
\text { Coniferous } \\
\text { tree }\end{array}$ & $\begin{array}{c}\text { Ej fastställd } \\
\text { Not } \\
\text { detectable }\end{array}$ \\
\hline 2 & $1 \mathrm{maj}$ & 0 & 0 & 3 & 0 & 4 \\
3 & $4 \mathrm{maj}$ & 3 & 1 & 1 & 0 & 6 \\
4 & $9 \mathrm{maj}$ & 10 & 5 & 1 & 0 & 14 \\
5 & $12 \mathrm{maj}$ & 1 & 2 & 1 & 0 & 4 \\
6 & $14 \mathrm{maj}$ & 1 & 1 & 2 & 0 & 4 \\
7 & $15 \mathrm{maj}$ & 1 & 1 & 5 & 0 & 0 \\
8 & $17 \mathrm{maj}$ & 2 & 0 & 2 & 0 & 2 \\
\hline Summa Total & & 18 & 10 & 15 & 0 & 34 \\
\hline
\end{tabular}


ande gransångare och 37 observationer av sjungande lövsångare under inventeringarna $\mathrm{i}$ villakvarteren vilket ger ett förhållande på 3 till 1 .

Exemplet ovan visar att enstaka räkningar av förmodat häckande fåglar även långt fram på våren kan ge missvisande värden och att upprepade besök (revirkartering) behövs. Att fastställa revir är dock inte okomplicerat. Undersökningen genomfördes med täta inventeringar vilket skulle kunna leda till att en rastande fågel som hörs under några dagar i tät följd för att sedan ge sig av skulle kunna ge en falsk revirindikation. Fåglarna verkar också röra sig inom området en tid innan de fastställt sitt revir. I två fall så sjöng en fågel vid tre inventeringar i rad från en plats för att sedan tystna under resten av inventeringarna. Istället dök det upp en fågel på en plats ett kort avstånd från den första och sjöng därifrån under resten av inventeringarna. Speciellt gransångarna kändes rörliga under inventeringarna, kanske som en effekt av att en del av trädgårdarna är stora och också har stora öppna ytor, en förflyttning från en sångplats till nästa blir då märkbar.

Förhållandet mellan antalet gransångarrevir och lövsångarrevir beräknat på revir med tre sångmarkeringar som grund blev i villakvarteren 2,6 till 1, vilket ungefär motsvarar förhållandet baserat på antalet sjungande fåglar.

För att få en jämförelse till villakvarteren inkluderades en del av rekreationsområdet Ribersborg i undersökningen. I detta område gjordes endast 4 observationer av sjungande gransångare och totalt 26 observationer av sjungande lövsångare (Tabell 2). Inget gransångarrevir konstaterades medan det fanns 5 lövsångarrevir. Inte bara Ribersborgsområdet avviker från villaområdena utan även sinsemellan skiljer sig de olika villaområdena åt. I området Nya Bellevue fanns det av någon anledning inga lövsångarrevir alls (Tabell 3). I området Västervång var tätheten av gran- och lövsångare lika hög (Tabell 3).

I Västervång noterades på två platser att ett gransångarrevir och ett lövsångarrevir i praktiken överlappade varandra (Figur 2 och 3). Att gran- och lövsångare kan ha överlappande revir finns belagt i tidigare undersökningar. I en studie utförd i en skog av gråal i Norge konstaterar Sæther (1982) att ett revir som ett år hålls av en lövsångare nästa år mycket väl kan hållas av en gransångare och tvärt om. Han menar vidare att hur arterna fördelar reviren i ett område kan bero på många faktorer och han finner i sin studie i denna biotop inget belägg för att olika områdespreferenser kan förklara fördelningen. I de experiment med interaktioner mel- lan arterna som han utförde visar sig ingen av arterna dominera över den andra (Sæther 1982).

Samtidigt som inventeringsresultatet visar att de kan samexistera verkar det finnas olika faktorer som påverkar fördelningen av arterna i de olika villaområdena.

Tidpunkten på våren när fåglarna anländer till häckplatsen kan troligen vara en konkurrensfaktor både inom och mellan arter. Under den kalla våren 2013 var dock skillnaden i ankomsttid till häckplatserna mellan gran- och lövsångaren ovanligt liten (egna observationer) och skillnaden mellan antal gran- och lövsångare i inventeringen beror troligen på något annat. En möjlig förklaring till skillnaderna skulle kunna vara den urbana miljön i sig. Dessa miljöer skiljer sig ofta från naturliga skogar i det att vegetationstäcket är tunnare, lägre växtskikt kan vara reducerade eller helt saknas och vegetationsområdena är ofta mycket mer sönderbrutna. Dessutom påverkas fåglar i urbana miljöer av en mängd störningar som inte finns i naturliga miljöer.

Jokimäki (1999) konstaterade att arter som lövsångare och skata Pica pica häckade i större omfattning i parker som hade en mer begränsad skötsel jämfört med mer välskötta parker. Skillnaden uppstod troligen som en effekt av att vegetationstäcket i den mer orörda parken då var tätare. Jokimäki (1999) konstaterar också i sin undersökning att antalet närliggande byggnader påverkar tre fågelarter negativt, nämligen lövsångaren, kråkan Corvus corone och den grå flugsnapparen Muscicapa striata. Det finns indikationer i den nu genomförda undersökning som talar för att de ovan nämnda faktorerna kan vara inblandade i skillnaderna i tätheter mellan inventeringsområdena.

På Ribersborgsområdet återfanns tre av lövsångarreviren i områden med tät markvegetation, medan området Nya Bellevue, som helt saknar lövsångarrevir, är det av villaområdena där vegetationstäcket är som mest uppbrutet och där det också är relativt tätt mellan husen. Möjligen indikerar detta att lövsångaren är mer kritiskt beroende av ett ordentligt örtskikt och en mindre tät bebyggelse för att trivas.

Cramp (1992) beskriver gransångaren som mindre attraherad av yngre och tätare vegetation eller av stora skuggiga skogspartier. Arten föredrar istället gläntor och trädridåer om det i området också finns några stora välväxta träd. I de nu undersökta villaområdena är trädgårdarna gamla och det finns en hel del stora träd. I området Bellevue bedöms det finnas flest riktigt stora och mäktiga träd, och i detta område är också revirtätheten för gransångare som högst, 18,7 par $/ \mathrm{km}^{2}$.

Vid inventeringarna gjordes försök att undersöka 
vilka preferenser de olika arterna har då de väljer sångplats (Tabell 4 och 5). Gransångaren noterades i många olika trädslag, medan lövsångaren verkade undvika barrträd. Några riktigt säkra slutsatser kan dock inte dras eftersom antalet ej fastställda sångplatser var ganska stort och fördelningen av tillgängliga träd inte skattades. Mer systematiska undersökningar måste därför göras för att säkerställa vilka bakomliggande skillnader i miljön som orsak till skillnaden mellan arternas revirtäthet i de olika delområdena.

Under projektets gång konstaterades att inventeringsmetoden verkade fungera väl. Då alla sjungande fåglar uppsöktes konstaterades att hela inventeringsområdet täcktes av mycket väl. En erfarenhet från inventeringarna var att gransångarens styltiga sång lättare uppfattas på riktigt långt håll jämfört med lövsångarens, men lövsångarens sång bar dock tillräckligt för att bli väl avlyssnad på rutten.

Den genomförda inventeringen har, både genom att räkna antalet sjungande individer vid olika inventeringstillfällen men också genom att göra en enklare form av revirkartering, visat att gransångaren är vanligare än lövsångaren i villakvarter i sydvästra Malmö. Är det rent av så att vi kan förvänta oss att gransångaren - som invandrat från söder och som haft gott om tid att anpassa sig till urbana miljöer i Centraleuropas gamla städer - kommer att bli städernas vanligaste Phylloscopus? Eller är den redan det?

\section{Tack}

Tack till Kenneth Bengtsson för information om tidigare inventeringsresultat, till Örjan Östman för kloka synpunkter på den första versionen av uppsatsen (ett projektarbete på en kurs i fågelinventeringsmetodik vid Uppsala universitet), till HansGünther Bauer och Martin Flade för hjälp med litteratur, samt till Åke Lindström för uppmuntran och många värdefulla synpunkter på manuskriptet.

\section{Referenser}

Bengtsson, K. \& Green, M. 2013. Skånes Fågelatlas. Skånes Ornitologiska Förening, Vellinge.

Bengtsson, K. \& Larsson, P. G. Inventering av häckfågelfaunan i Burlövs kommun 1991. Anser 31: 17-26.

Cramp, S. (ed.) 1992. Handbook of the Birds of Europe, the Middle East and North Africa: The Birds of the Western Palearctic. Vol 6. Oxford University Press, Oxford.

Flade, M. 1994. Die Brutvogelgemeinschaften Mittel- und Norddeutschlands. IHW-Verlag, Eching.

Gedeon, K., Grüneberg, C., Mitschke, A., Sudfeldt, C., Eik- horst, W., Fischer, S., Flade, M., Frick, S., Geiersberger, I., Koop, B., Kramer, M., Krüger, T., Roth, N., Ryslavy, T., Schlotmann, F., Stübing, S., Sudmann, S. R., Steffens, R., Vökler, F. \& Witt, K. (2014, in press): Atlas Deutscher Brutvogelarten. Stiftung Vogelmonitoring Deutschland und Dachverband Deutscher Avifaunisten. HohensteinErnstthal and Münster.

Green, M. \& Lindström, Å. 2014. Övervakning av fåglarnas populationsutveckling. Arsrapport för 2013. Rapport, Biologiska institutionen, Lunds Universitet. 78 pp.

Jokimäki, J. 1999. Occurrence of breeding bird species in urban parks: Effects of park structure and broad-scale variables. Urban Ecosystems 3: 21-34

Lindström, Å., Svensson, S., Green, M. \& Ottvall, R. 2007. Distribution and population changes of two subspecies of Chiffchaff Phylloscopus collybita in Sweden. Ornis Svecica 17: 137-147.

Ottosson, U., Ottvall, R., Elmberg, J., Green, M., Gustafsson, R., Haas, F., Holmqvist, N., Lindström, Å., Nilsson, L., Svensson, M., Svensson, S. \& Tjernberg, M. 2012. Fåglarna i Sverige - antal och förekomst. Sveriges Ornitologiska Förening, Halmstad.

Peterz, M. \& Rellmar, M. 2007. Inventering av Kullabergs häckfåglar 2004. Anser 46: 1-26.

Sæther, B-E. 1982. Mechanism of interspecific spacing out in a territorial system of the Chiffchaff Phylloscopus collybita and the Willow Warbler P. trochilus. Ornis Scandinavica 14: 154-160.

Svensson, S., Svensson, M. \& Tjernberg, M. 1999. Svensk Fågelatlas. Vår Fågelvärld, suppl. 31, Stockholm.

\section{Summary}

The number of singing Chiffchaffs Phylloscopus c. collybita and Willow Warblers Ph. trochilus were counted in spring 2013 in a suburb of the city of

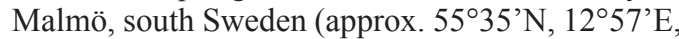
Figur 1). Eight visits were paid between 28 April and 17 May to three sub-areas dominated by villas and their grown-up gardens (total area of $1.27 \mathrm{~km}^{2}$ ) and a reference area with large lawns, a long row of trees and some very small woods (total area of $0.46 \mathrm{~km}^{2}$ ). The censuses were carried out by bike between 05.00 and 07.00 local time. The number of territories was also estimated, based on at least three encounters at the same site during the study period. The tree species the bird was sitting in was also recorded.

The numbers of singing Chiffchaffs in the three villa areas varied between 12 and 18 per census, with an average of 15.3 and a standard deviation of \pm 2.8 (Table 1, Figure 1). The corresponding values for Willow Warblers were 4 and 20 (average 7,1 \pm $5,5)$. In the reference area there were many more Willow Warblers than Chiffchaffs (Table 2).

During census 4 there was most likely a heavy landfall of migrating Willow Warblers, and observations from this day were not included when es- 
timating territories. The total number of territories in the villa areas was 21 for Chiffchaff and 8 for Willow Warbler, which is equal to a density of 16.5 and 6.3 pairs $/ \mathrm{km}^{2}$ (Table 3, Figure 2 and 3). The choice of tree species for song posts differed somewhat between the species, with Willow Warblers seemingly avoiding coniferous trees (Table 4 and $5)$.

The Chiffchaff density of 16.5 pairs $/ \mathrm{km}^{2}$ is probably the highest ever recorded in Sweden in such a large census plot (cf. Peter \& Rellmar 2007, Ottosson et al. 2012), which is not surprising given the enormous population increase the collybita subspecies has had the last 40 years in south Sweden, with an average annual increase of $9.6 \%$ /year.
(Lindström et al. 2007, Green \& Lindström 2014). The density found also matches well the highest found in German urban areas (Flade 1994, Gideon et al. 2014).

The Willow Warbler density of 6.3 pairs $/ \mathrm{km}^{2}$ is in line with previous values for urban areas, but much lower than the $100-250$ pairs $/ \mathrm{km}^{2}$ that can be found in the most optimal habitats, such as old clear-cuts with dense stands of growing birch (Ottosson et al. 2012).

The difference in density between the two species in this villa suburb may be the Chiffchaff's relative preference for areas with large trees, interspersed by open areas with less understory. 